\title{
Erratum to "Complementary and Alternative Medicine Education for Medical Profession: Systematic Review"
}

\author{
Nana K. Quartey, Polly H. X. Ma, Vincent C. H. Chung, and Sian M. Griffiths \\ School of Public Health and Primary Care, Chinese University of Hong Kong, Hong Kong \\ Correspondence should be addressed to Vincent C. H. Chung, vchung@cuhk.edu.hk \\ Received 21 October 2012; Accepted 23 October 2012 \\ Copyright (C) 2012 Nana K. Quartey et al. This is an open access article distributed under the Creative Commons Attribution \\ License, which permits unrestricted use, distribution, and reproduction in any medium, provided the original work is properly \\ cited.
}

In the original paper, the table describing characteristics of included studies on page 4 (Table 1) includes an error. The "Duration and frequency of intervention" of Donald et al.'s study should be "One-off intervention lasting half a day," rather than "Not reported." 


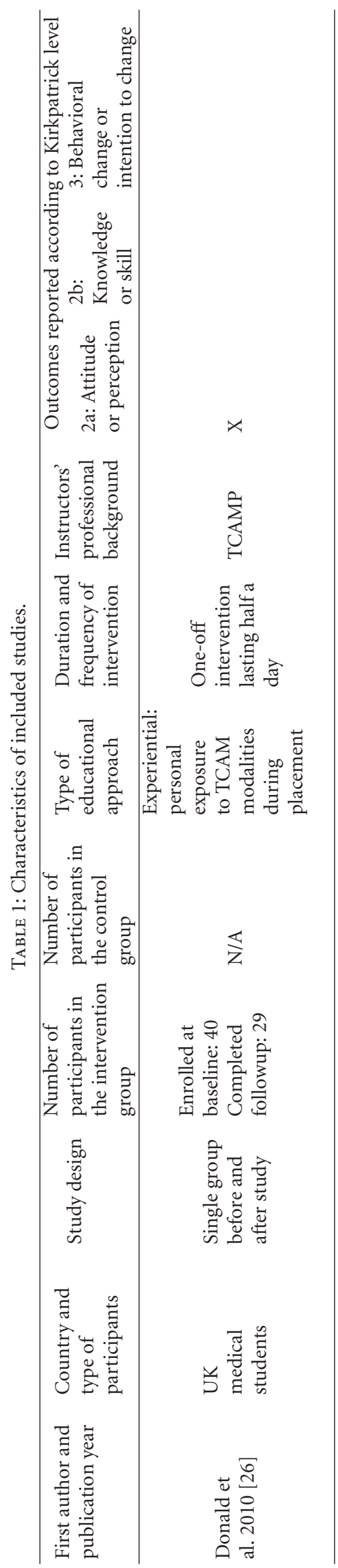




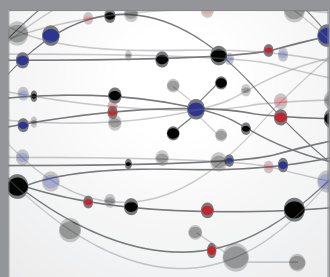

The Scientific World Journal
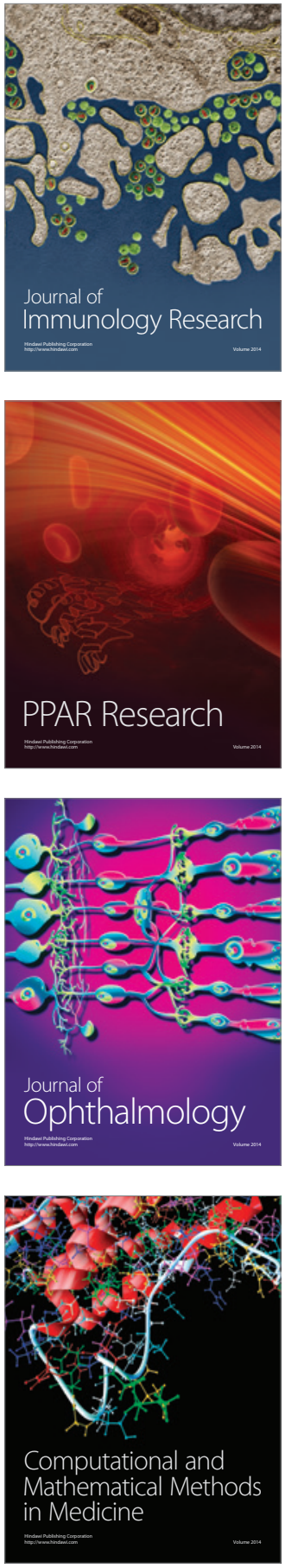

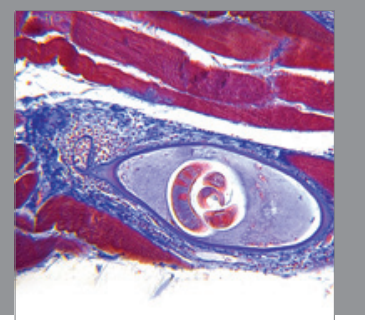

Gastroenterology

Research and Practice
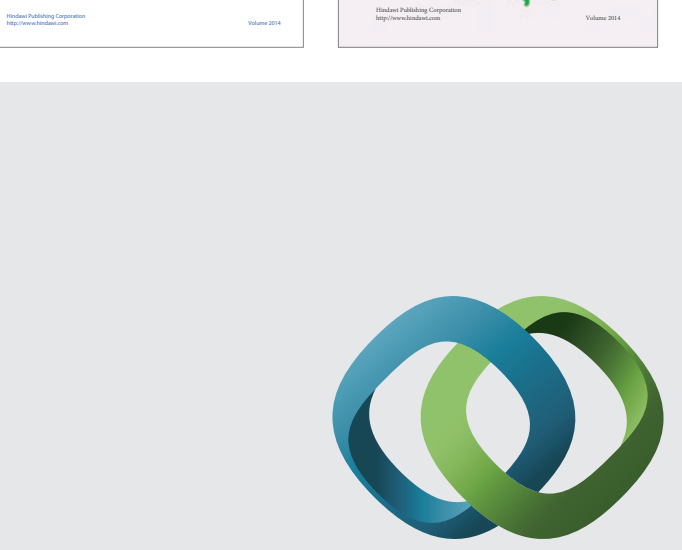

\section{Hindawi}

Submit your manuscripts at

http://www.hindawi.com
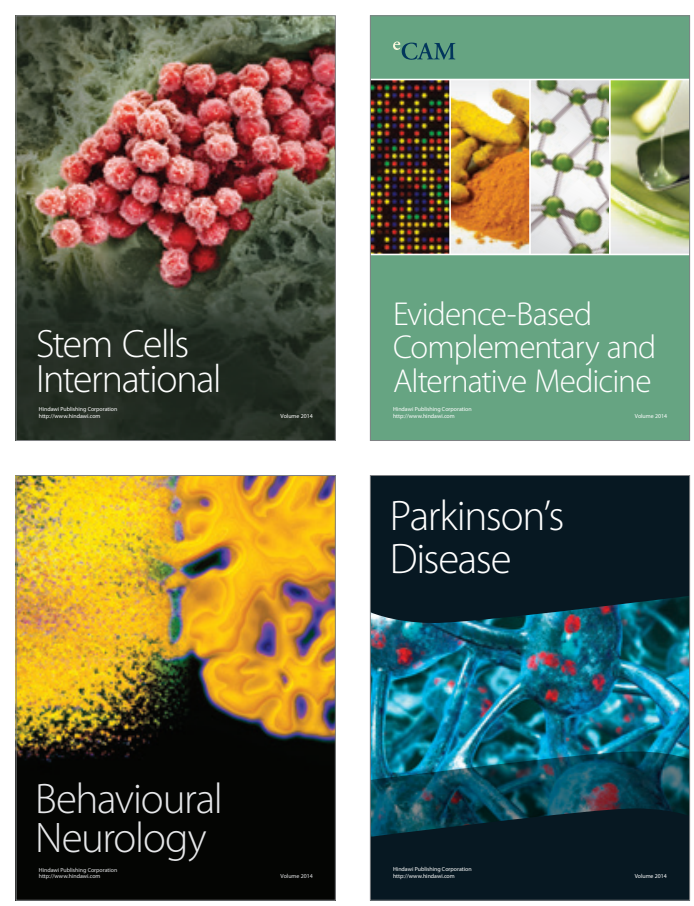

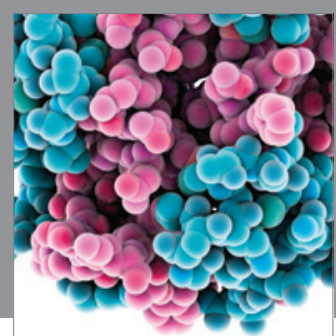

Journal of
Diabetes Research

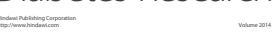

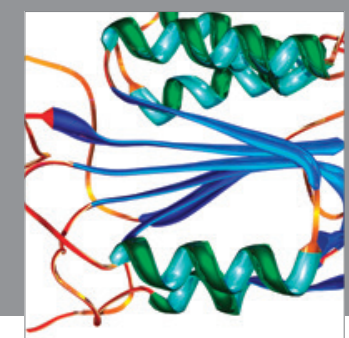

Disease Markers
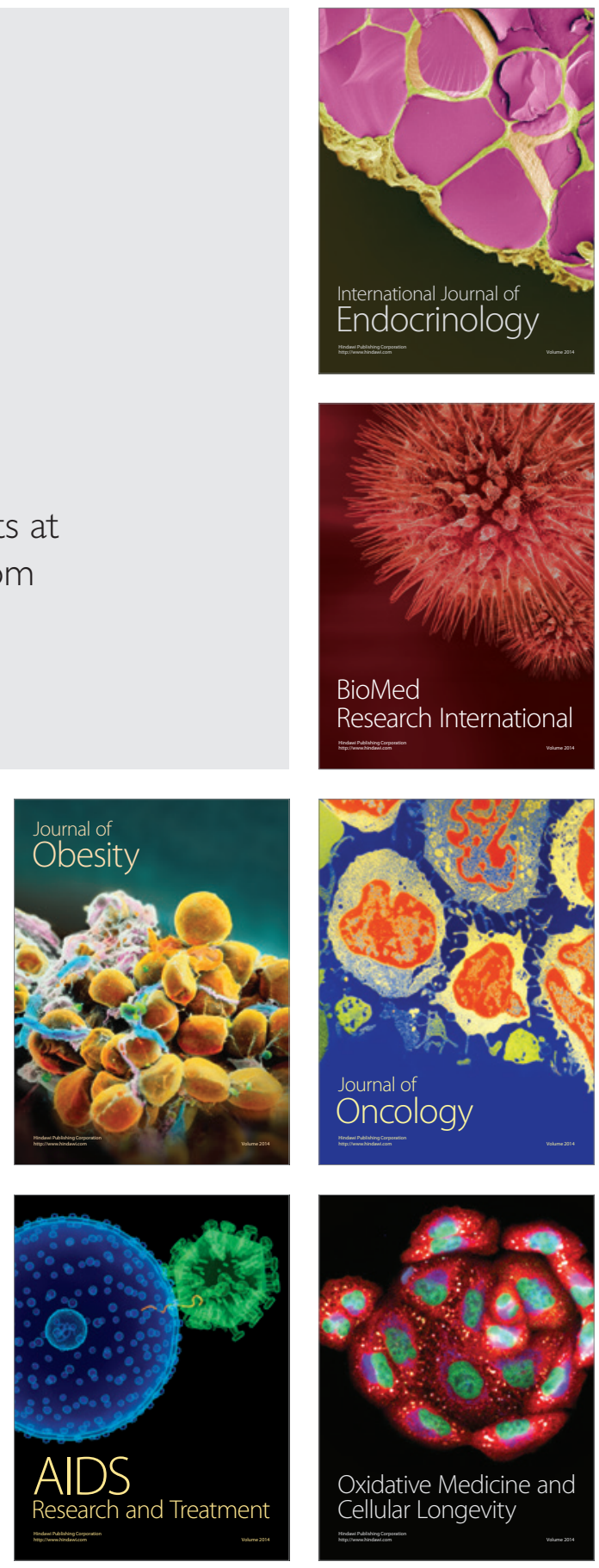